Max has been a member of the Governing Board of the Student Outreach Resource Center (SOURCE) at Johns Hopkins for 3 years. He is a co-leader of his medical school's Urban Health Interest Group and Family Medicine Interest Group, he sat on the board of the Maryland Academy of Family Physicians Foundation, and he served as a Student Delegate to the National Congress of Student Members of the American Academy of Family Physicians (AAFP). Recently, Max was appointed to a 1-year term on the AAFP's Commission on Health of the Public and Science and was named a Sommer Scholar at the Johns Hopkins Bloomberg School of Public Health.

As a future family physician, Max looks forward to practicing community-based primary care and preventive medicine. He wants to bring innovative models of primary care delivery to underserved communities and provide coordinated, comprehensive, and compassionate care to his patients.

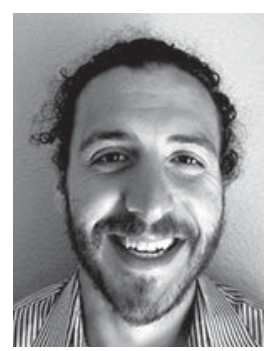

Chas Salmen, a 2013 Pisacano Scholar, is a 4th-year medical student at the University of California, San Francisco School of Medicine (UCSF). He graduated with honors from Duke University with a Bachelor of Arts in English Literature. He was awarded a Rhodes Scholarship where he was awarded highest distinction upon receiving his Master in Medical Anthropology.

At Duke, Chas was captain of the varsity cross country and track and field teams. Chas was also the founder and chairman of Peace or Pieces, an Arab-Jewish Student Coalition that raised over $\$ 20,000$ for twin communities in Southern Lebanon and Northern Israel.

Chas is the founding director of The Organic Health Response (OHR) in Kenya. Today, OHR has an annual budget of over $\$ 250,000$ per year and is a US-based 501c3 nonprofit and a registered Community-Based Organization in Kenya. Chas directs a team of 12 USbased staff and volunteers and 42 full-time Kenyan staff

As a medical student, Chas was awarded the UCSF School of Medicine Dean's Yearlong Research Fellowship. He is the senior vice-president of MicroClinic International (MCI), a global nonprofit with programs in Jordan, India and Appalachia-USA. Chas secured a $\$ 100,000$ catalyst grant to launch the world's first MicroClinic program for HIV/AIDS on Mfangano Island.

Chas looks forward to continuing his clinical training as a rural family physician. Eventually, he hopes to build a community-based practice in the rural Midwest while continuing to grow clinical services on Mfangano Island, Kenya.


From the Association of Family Medicine Residency Directors


Ann Fam Med 2014;83-87. doi: 10.1370/afm.1608.

\section{THE FOUR PILLARS FOR PRIMARY CARE PHYSICIAN WORKFORCE REFORM: A BLUEPRINT FOR FUTURE ACTIVITY}

The passage of the Affordable Care Act and the introduction of health insurance exchanges are increasing demand for a primary care physician workforce able to manage populations, deliver care within inter-professional teams, and address quality outcomes of practice. Nevertheless, national statistics demonstrate that an insufficient number of students and residents are choosing primary care careers. ${ }^{1-5}$ Family medicine organizations and researchers have identified factors that influence specialty choice including individual learner characteristics, training and practice environments, and payment systems, ${ }^{6-11}$ and national debates continue the conversation about physician workforce. ${ }^{12}$ This paper presents a framework with consistent language to guide our efforts to increase production of well-trained primary care physicians for our populations.

The Council of Academic Family Medicine (CAFM), representing the family medicine academic organizations, has adopted the "Four Pillars for Primary Care Physician Workforce" as a succinct model to identify necessary conditions to ensure the needed growth in the number of primary care physicians. We are very pleased that other family medicine organizations, including the American Academy of Family Physicians (AAFP), the American Board of Family Medicine (ABFM), and the AAFP Foundation have joined CAFM in embracing this model and language as a blueprint for growing the number of primary care physicians. We expect that this conceptualization 
Figure 1.

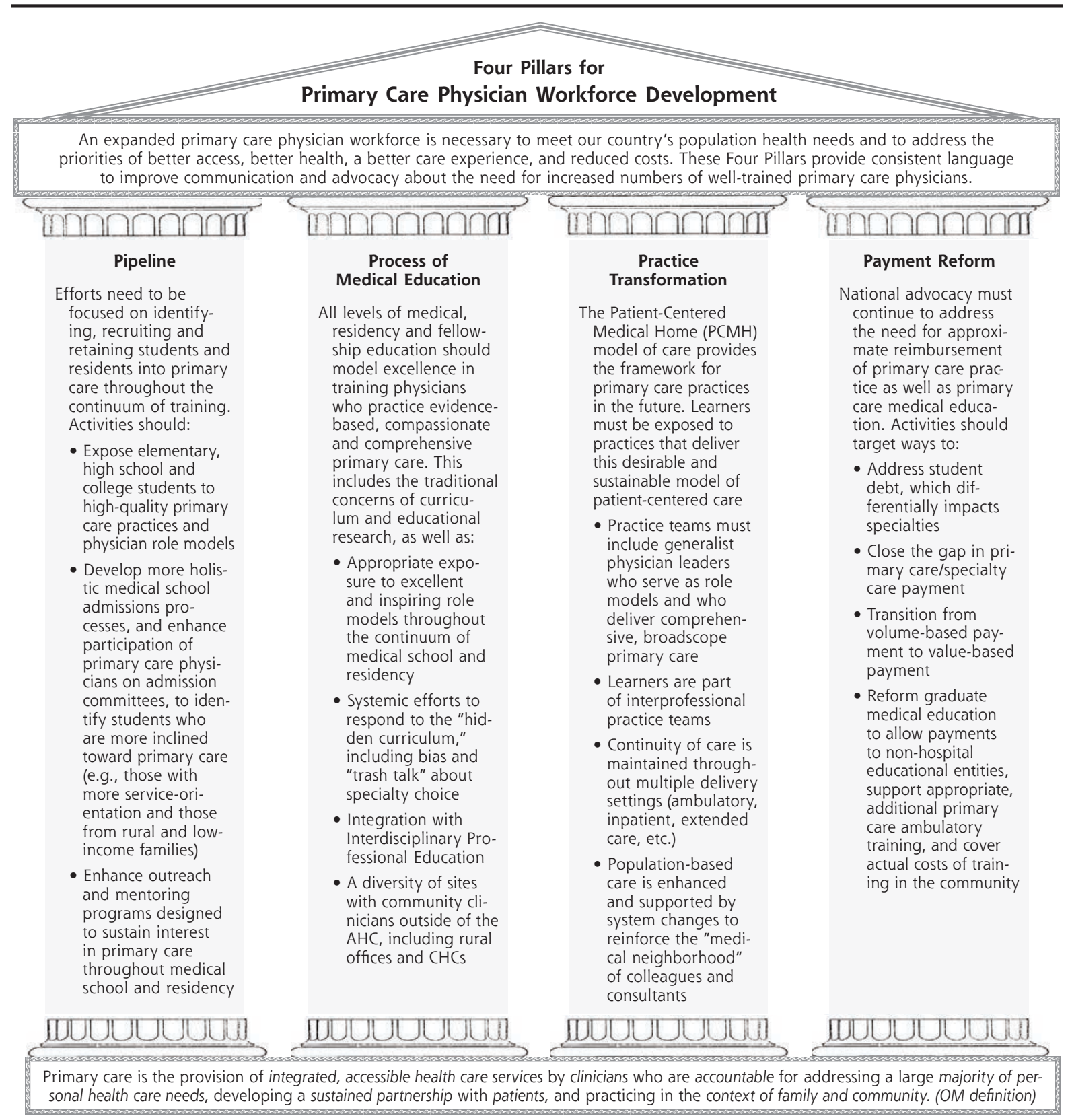

Developed by the Family Medicine Organizations (9/3/13)

and terminology can help our organizations provide consistent messaging for advocacy for appropriate primary care workforce development programs. We also anticipate that this framework might be useful for the broader primary care community as we seek ways to work together in pursuit of our shared goal of access to quality health care for the American public.

Efforts to develop an appropriate primary care workforce include attention to each of the four pillars:
- Pipeline

- Process of medical education

- Practice transformation

- Payment reform

Each of these pillars will be described, and a concluding section will address how this conceptual model may help focus training and advocacy activities needed to develop the primary care physician workforce required to meet the needs of our nation's populations. 


\section{Pipeline}

This first pillar relates to the continuum of identifying, recruiting, and sustaining those students who are most likely to seek careers as primary care physicians. The pipeline process actually begins in the early school years as students are exposed to role model primary care physicians in their communities and includes an educational system with robust opportunities in math and science. It then continues through college as students begin to pursue pre-health educational pathways and interact with advisors and career counselors, who can provide support and information about being a primary care physician. Providing targeted college guidance counselors with information, resources, and materials is an example of a way to enhance the pipeline of those who may choose to become primary care physicians. But the pipeline for student interest in primary care cannot be dependent on a single strategy. Addressing the multiple considerations by which a student selects a career path requires a "portfolio approach" that touches upon the very personal questions impacting such an important, life-defining decision. The AAFP, for example, supports such a diverse approach to student interest, with details available at: http://www.aafp.org/medical-school-residency/ medical-school/specialty.html.

One of the most influential ways to favorably impact the pipeline is through the composition of the medical school admissions committee. ${ }^{7}$ Proactive efforts must increase the number of primary care physicians and other supporters of primary care on medical school admissions committees. They are in the best position to identify and advocate for applicants with the characteristics most predictive of medical students who will eventually pursue a career in primary care. These characteristics include applicants from a rural background, mature individuals with a broader life experience, students with lower income expectations or from lower socioeconomic backgrounds, and individuals with demonstrated evidence of an inclination toward public service and social consciousness. ${ }^{6-8,10,13}$

Developing and admitting applicants who are most likely to pursue primary care practice is the first pillar. Sustaining their interest throughout medical education requires proactive positive mentoring including peer support, such as primary care student interest groups, exposure to high-functioning primary care practices, and contact with effective primary care physicians with good work-life balance.

\section{Process of Medical Education}

The second pillar includes the traditional focus on curriculum development throughout medical student and residency education. Family medicine organizations, especially the Society of Teachers of Family Medicine (STFM) and the Association of Family Medicine Residency Directors (AFMRD), are recognized leaders throughout the medical education community for their focus on innovative curriculum, assessment and evaluation, and faculty development. Title VII programs have helped to support these innovations and to ensure evaluation and dissemination. More recent efforts toward competency assessment are reflective of our discipline's continual attention to creating accessible and effective curricula. Strong evidence supports the association between well-established academic departments of family medicine and clearly identified required curriculum time in family medicine and a medical school's primary care outcomes. ${ }^{7-8,10,14}$ The process of medical education should have these characteristics at every American medical school.

The process of medical education also includes attention to the "hidden curriculum" in medical schools. How is a career choice of primary care valued in an institution? A recent study of 20 medical schools by leaders in the Association of American Medical Colleges (AAMC) reported that students who attend schools with a higher reported percentage of disparaging comments or "badmouthing" of primary care, are less likely to choose primary care careers..$^{10}$ This highlights the need for increased leadership skills for family medicine educators within medical schools, not only on admission committees, but in senior leadership positions where they can help address culture and enhance professional respect. This recent report also suggests that the challenge is not just about attracting primary-care bound students into medical school. The challenge is also about retaining them throughout the four-year process of medical school education so that they graduate with the same or greater passion as when they entered.

Ensuring excellence in curriculum is the second pillar, but it is not just about "a curriculum"; it is about learners' experience of that curriculum. No matter how inspiring a curriculum, exposure to dissatisfied or disgruntled physicians negatively impacts primary care career choice. Students and residents experience curricula through real life clinical practices- they must be exposed to enthusiastic primary care physician mentors who are thriving in well-managed, sustainable practices.

\section{Practice Transformation}

The Patient-Centered Medical Home (PCMH) model of care provides the framework of primary care practice for the future. Thus, practice transformation is the third pillar. This may involve community activism and changes beyond the medical practice itself. Learners must be exposed to practices that deliver this desirable and sustainable model of patient-centered 
care. The Future of Family Medicine Project ${ }^{15}$ and the PCMH concepts directly address this pillar. Enhancement of training practices also increases the satisfaction and competence of potential role models. Core practice transformations include the following:

- Practice teams must include generalist physician leaders who serve as role models and deliver comprehensive, broad-scope primary care. Leadership is not defined by who is the boss, but reflects how team members have a voice in the mechanisms of care of patients and help to inform and change the system. Broad-based physician leaders will envision the direction of the practice's mission and vision of always keeping the patients' best interests at the forefront of decisions. Teams also need leaders from other health professions to reach optimal functioning and efficient care delivery.

- Learners are part of inter-professional practice teams, and are involved with continued education and opportunities to impact practice redesign to achieve effective, relationship-based care.

- Learners will be exposed to the continuous care of patients in multiple settings, including ambulatory, inpatient, extended, and home care. Communication will be both synchronous and asynchronous to enhance communication and build relationship and trust between the patient and their medical home.

- Population-based care is enhanced and supported by system changes to reinforce the "medical neighborhood" of colleagues and consultants. This population-based care will drive improvements in communities for the local needs of the patients to improve the overall health and well-being of our communities.

Creating sustainable practices that deliver highvalue, compassionate care is the third pillar. However, the decision to practice primary care is a choice about values and lifestyle, which must also be viewed as a financially sustainable choice.

\section{Payment Reform}

Because increases in primary care physician income are associated with dramatic and immediate increases in student choice of primary care careers, payment reform is the fourth pillar. Payment reform generally refers to income of practicing physicians, but comprehensive attention to payment reform requires reform of funding for medical education. A primary care physician workforce cannot grow without a sustainable methodology for financing the training of physicians, which includes medical student debt relief ${ }^{16}$ and new models for financing Graduate Medical Education (GME), particularly in ambulatory, community-based settings.

The most important predictor of specialty choice is the ratio of mean primary care income to mean specialty income (the income ratio). ${ }^{17}$ International comparative data shows that an income ratio in the range of 0.80 to 0.85 is associated with a $40 \%$ student preference for primary care career choice. The Altarum Institute performed a longitudinal study of income ratios and found a significant and reproducible correlation between the income ratio and primary care career choice. ${ }^{17-18}$ US medical student choice of primary care careers was highest at $40 \%$ when the income ratio was 0.78 in 1985 , and plummeted to its current level of $15 \%$ when the income ratio hit a low of 0.50 in 2007. This association, when combined with anticipated professional return on investment for number of years of training, suggests that an income ratio of about 0.80 will lead to an appropriately balanced US physician workforce.

Experiences in Canada and the United Kingdom validate the US data. In 1998, 34\% of Canadian medical students entered family medicine residencies. This percentage declined significantly to a low of $24 \%$ in 2004. Provincial governments and medical schools supported the institution of hefty prospective care coordination payments to family medicine centers, which stimulated practice transformation ${ }^{19}$ and increased family physician income by $50 \%$. The income ratio rose to 0.83 , with a resultant steady increase in student interest in family medicine. This interest hit an all-time high in 2013, when $42 \%$ of Canadian medical school graduates entered family medicine residency programs.

The United Kingdom phased in payments for quality indicators from 1991 to 2004 to improve clinical outcomes and to stimulate an increase in student family medicine career choice. Family physician income rose significantly to equal the mean specialty income in 2006 (income ratio 1.00). The British Medical Association Cohort Study reported medical student choice of family medicine careers more than doubled. ${ }^{19}$

These comparisons suggest that significant increases in payment to primary care practices through blended payments for fee-for-service, care coordination, and quality outcomes will lead to practice transformation and to a significant increase in student primary care career choice.

\section{Next Steps: Advocacy}

We are often asked, "What can we do to increase the number of primary care physicians?" The answer is the four pillars.

There are different audiences and key constituents for each of the four pillars. The first two pillars provide the outline for medical school deans, admissions, and curriculum committees, all experiencing more pressure to increase their numbers of primary care graduates. Nationally the four Pillars can frame work with the medical associations and accreditation bodies. 
To compete in the new, value-based health care system, both insurance companies and larger health care systems need more primary care physicians working in patient-centered medical homes. To achieve this, they must financially support the third pillar of practice transformation.

The final pillar of payment reform is clearly the most important and the most difficult to achieve. Balanced payment for primary care and specialty care is fundamental to meeting the triple aim of "better care, better health, lower costs". ${ }^{20}$ Our audiences include our federal and state legislators, insurers, health systems, and the public. Our partners are the AAFP, CAFM, our professional colleagues, and consumer groups. The "four pillars" is a powerful vehicle for promoting the expansion of the primary care workforce which can serve as an "elevator speech" to effectively communicate the key steps to increase the number of primary care physicians in the United States.

Jeri Hepworth, Ardis Davis, Amanda Harris, Jerry Kruse,

Todd Shaffer, Perry Pugno, Tom Campbell, John Saultz and members of the CAFM Four Pillars Taskforce* Council of Academic Family Medicine (CAFM) Four Pillars *Taskforce: Jeri Hepworth, Chair Ardis Davis, Amanda Harris, Staff Tom Campbell, Valerie Gilchrist, Perry Pugno, Jobn Saultz, Todd Shaffer, Hope Wittenberg

\section{References}

1. Petterson SM, Liaw WR, Phillips RL Jr, Rabin DL, Meyers DS, Bazemore AW. Projecting US primary care physician workforce needs: 2010-2025. Ann Fam Med. 2012;10(6):503-509.

2. Dill MJ, Salsberg ES. The Complexities of Physician Supply and Demand: Projections Through 2025. Washington, DC: Association of American Medical Colleges; 2008. http://www.innovationlabs.com/ pa_future/1/background_docs/AAMC\%20Complexities $\% 20$ of $\% 20$ physician\%20demand,\%202008.pdf. Accessed Nov 6, 2013.

3. Health Resources and Services Administration. The Physician Workforce: Projections and Research Into Current Issues Affecting Supply and Demand. Rockville, MD: US Department of Health and Human Services; 2008. http://bhpr.hrsa.gov/healthworkforce/reports/physwfissues.pdf. Accessed Nov 6, 2013.

4. Kirch DG, Henderson MK, Dill MJ. Physician workforce projections in an era of health care reform. Annu Rev Med. 2012;63:435-445.
5. Biggs WS, Crosley PW, Kozakowski SM. Results of the 2013 National Resident Matching Program: family medicine. Fam Med. 2013;45(9):647-651.

6. Nicholson S, Souleles NS. Physician Income Expectations and Specialty Choice. Working Paper 8536. Cambridge, MA: National Bureau of Economic Research; 2001. http://www.nber.org/papers/w8536. Accessed Nov 6, 2013.

7. Senf JH, Campos-Outcalt D, Watkins AJ, Bastacky S, Killian C. A systematic analysis of how medical school characteristics relate to graduates' choices of primary care specialties. Acad Med. 1997;72(6): 524-533.

8. Senf JH, Campos-Outcalt D, Kutob R. Factors related to the choice of family medicine: a reassessment and literature review. J Am Board Fam Pract. 2003;16(6):502-512.

9. Senf JH, Kutob R, Campos-Outcalt D. Which primary care specialty? Factors that relate to a choice of family medicine, internal medicine, combined internal medicine-pediatrics, or pediatrics. Fam Med. 2004;36(2):123-130.

10. Erikson CE, Danish S, Jones KC, Sandberg SF, Carle AC. The role of medical school culture in primary care career choice. [published online ahead of print October 14, 2013]. Acad Med. 2013;88(12):1919-1926.

11. Clinite KL, Reddy ST, Kazantsev SM, et al. Primary care, the ROAD less traveled: what first-year medical students want in a specialty. Acad Med. 2013;88(10):1522-1528.

12. Redesigning the Health Care Workforce [journal issue]. Health Aff(Millwood). 2013;32(11):1871-2060.

13. Jeffe DB, Whelan AJ, Andriole DA. Primary care specialty choices of United States medical graduates, 1997-2006. Acad Med. 2010; 85(6):947-958.

14. Bland CJ, Meurer LN, Maldonado G. Determinants of primary care specialty choice: a non-statistical meta-analysis of the literature. Acad Med. 1995;70(7):620-641.

15. Martin JC, Avant RF, Bowman MA, et al.; Future of Family Medicine Project Leadership Committee. The Future of Family Medicine: a collaborative project of the family medicine community. Ann Fam Med. 2004;2(Suppl 1):S3-S32.

16. Asch DA, Nicholson S, Vujicic M. Are we in a medical education bubble market? N Engl J Med. 2013;369(21):1973-1975.

17. Council on Graduate Medical Education. Twentieth Report: Advancing Primary Care. December 2010. http://www.hrsa.gov/advisorycommittees/bhpradvisory/cogme/Reports/twentiethreport.pdf. Accessed Nov 7, 2013.

18. Kruse J. Income ratio and medical student specialty choice: the primary importance of the ratio of mean primary care physician income to mean consulting specialist income. Fam Med. 2013;45(4):281-283.

19. Rosser WW, Colwill JM, Kasperski J, Wilson L. Patient-centered medical homes in Ontario. N Engl J Med. 2010;362(3):e7. 10.1056/ NEJMp091151.

20. Berwick DM, Nolan TW, Whittington J. The triple aim: care, health, and cost. Health Aff (Millwood). 2008;27(3):759-769. 